DOI: 10.12731/2070-7568-2021-10-3-26-40

УДК 33

\title{
ПРИМЕНЕНИЕ НЕЙРОННЫХ СЕТЕЙ ДЛЯ ОЦЕНКИ ЭКОНОМИЧЕСКОЙ БЕЗОПАСНОСТИ
}

\author{
Гонтарь А. $A$.
}

В современных обстоятельствах хозяйствования значимое влияние на экономические прочессы любого государства имеет финансовый сектор. По этой причине усиливается роль анализа деятельности коммерческих банков, в частности, системы экономической безопасности. Огромное количество кредитных учреждений формируют отделения по исследованию и управлению рисками, при этом за пределами внимания специалистов остаются некоторые нюансы анализа текущего состояния системы экономической безопасности банков. Возникает потребность в комплексном подходе и в продуманной тактике для повышения уровня экономической безопасности кредитных учреждений. В научной статье рассматриваются ключевые методы оценки экономической безопасности: количественный анализ текущих показателей, ранжирование на основе пресс-рейтинга, авторские методики. Выявлены основные недостатки существующих подходов, а также определена система показателей экономической безопасности на примере кредитной организации.

Цель - реализаџия и построение нейросетевой модели, позволяющеей прогнозировать значения уровня экономической безопасности.

Метод или методология проведения работы. Для реализации поставленной цели были использованы общенаучные методы (анализ, синтез, индукция, дедукция, обобщение), а также методы нейросетевого моделирования.

Результаты. В научной статье рассматриваются ключевые методы оценки экономической безопасности: количественный анализ текущих показателей, ранжирование на основе пресс-рейтинга, 
авторские методики. Выявлены основные недостатки существующихх подходов, а также определена система показателей экономической безопасности на примере кредитной организации.

Область применения результатов. Реализация нейросетевой модели (на примере ПАО Сбербанк) позволяет прогнозировать итоговые значения целевой функции и аппроксимировать нелинейные входные данные. Моделирование уровня экономической безопасности дает возможность выявить существующие проблемы, предупредить негативные последствия необоснованных управленческих решений.

Ключевые слова: модель; нейросеть; показатели; прогнозирование; экономическая безопасность

\section{APPLICATION OF NEURAL NETWORKS FOR THE ASSESSMENT OF ECONOMIC SECURITY}

\section{Gontar A.A.}

In modern economic conditions, the financial sector has a significant impact on the economic processes of any state. For this reason, the role of analyzing the activities of commercial banks, in particular, the economic security system, is increasing. A huge number of credit institutions form research departments, while some of the nuances of analyzing the current state of the economic security system of banks remain outside the scope of attention. There is a need for an integrated approach and well-thought-out tactics to increase the level of economic security of credit institutions. The scientific article examines the key methods for assessing economic security: quantitative analysis of current indicators, ranking based on press rating, author's methods. The main disadvantages of the existing approaches are revealed, and the system of indicators of economic security is determined as in the case of a credit institution.

Purpose. The goal is the implementation and construction of a neural network model that makes it possible to predict the values of the level of economic security. 
Methodology to achieve the goal, general scientific methods were used (analysis, synthesis, induction, deduction, generalization), as well as methods of neural network modeling.

Results: the scientific article discusses the key methods for assessing economic security: quantitative analysis of current indicators, ranking based on press rating, author's methods. The main disadvantages of the existing approaches are revealed, and the system of indicators of economic security is determined by way of the example of a credit institution.

Practical implications implementation of a neural network model (using the example of Sberbank PJSC) makes it possible to predict the final values of the objective function and approximate nonlinear input data. Modeling the level of economic security gives the opportunity to identify existing problems, to prevent the negative consequences of unreasonable management decisions.

Keywords: model; neural network; indicators; forecasting; economic security

\section{Введение}

Дестабилизация экономики в условиях пандемии COVID-19 способствует негативным тенденциям в макро- и микроэкономических процессах. По мнению экспертов последствия экономического спада по сравнению с кризисами 2008 и 2014 гг. будут самыми существенными [6]. В 2021 году МФВ прогнозирует рецессию мировой экономики. В сложившейся кризисной ситуации именно финансовые институты выступают в роли источника государственной поддержки. Массовое закрытие вкладчиками депозитных счетов, возросший риск ликвидности, кредитный риски другие разновидности рисков могут стать причиной банкротства большого числа кредитных учреждений. В таких кризисных условиях необходимо объективно и более детально оценивать уровень экономической безопасности деятельности коммерческих банков. Согласно зарубежной практике, экономическая безопасность является основой государственной экономической независимости, способствуя социально-экономическому благосостоянию общества, ослабляя со- 
циальные противоречия и повышая благосостояния граждан [1]. Экономическая безопасность страны во многом определяется уровнем развития национальной банковской системы и ее конкурентоспособностью на мировом рынке финансовых услуг [5; 7; 8; 14; 15$]$. Как известно, в марте 2021 года рейтинговое агентство Fitch снизило прогноз российской банковской системы со «стабильного» на «негативный», однако крупнейшие отечественные банки, такие как Банк ВТБ и ПАО Сбербанк, по-прежнему претендуют на достойное место в мировом финансовом рынке. В этой связи повышение экономической безопасности России, в частности, обеспечение экономической безопасности национальной банковской системы, можно считать одной из первоочередных и ключевых задач национального развития. Целью научной статьи является обоснование выбора показателей финансовой отчетности деятельности коммерческого банка, характеризующих уровень экономической безопасности, а также разработка модели для оценки уровня экономической безопасности кредитной организации.

\section{Материалы и методы}

В настоящее время существует три основных метода оценки экономической безопасности кредитной организации. Первый из них - подход, описанный в указании Банка России от 11 июня 2014 г. № 3277-У (ред. от 26.12.2017) «О методиках оценки финансовой устойчивости банка в целях признания ее достаточной для участия в системе страхования вкладов», на указании Банка России от 3 апреля 2017 г. № 4336-У «Об оценке экономического положения банков», а также на данных финансовой отчетности [9]. Основным недостатком подхода, используемого ЦБ РФ является отсутствие прогнозных показателей, методика предусматривает только количественный анализ текущих показателей, что исключает динамичность в оценке уровня экономической безопасности. Вторую группу подходов к оценке экономической устойчивости составляют методики различных международных и национальных рейтинговых агентств, консультационных компаний, печатных изданий (например, рейтинговые агентства 
«Коммерсант», Moody’s, Fitch Ratings, журнал «Эксперт», межбанковское объединение «Огрбанк» и др.) [16]. Итоговое значение уровня экономической безопасности коммерческого банка, в таком случае, в большей степени основывается на расчете пресс-рейтинга, что не всегда является объективным показателем экономической деятельности кредитной организации, поскольку мнение прессы может быть обусловлено, например, национальными интересами государства, а не реальными показателями экономической деятельности. Таким образом, при составлении рейтинга не учитываются количественные показатели, что, несомненно, является существенным недостатком применяемых методик $[10 ; 13]$. Третью группу подходов к исследованию и оценке уровня экономической безопасности коммерческого банка составляют авторские методики, наиболее широкое применение в отечественной практике нашла методика В.С. Кромонова. Суть подхода заключается в сравнении показателей экономической деятельности кредитной организации с показателями «идеального банка». Данная методика субъективна, так как отсутствует формализация правил определения количественных оценок «идеального банка», учитывается только мнение эксперта [3].

Наиболее объективным подходом в данном контексте, по мнению авторов, является методика ЦБ РФ, поскольку учитывает только количественные характеристики экономической деятельности. Согласно инструкции ЦБ 139-И для объективной оценки уровня экономической безопасности коммерческого банка достаточно рассмотреть следующую группу показателей деятельности коммерческого банка: норматив достаточности собственных средств Н1.0; рентабельность капитала; рентабельность активов-нетто; норматив мгновенной ликвидности Н2; норматив текущей ликвидности Н3.

В работах $[2 ; 4 ; 11 ; 12]$ предложена и обоснована нейросетевая модель оценки уровня экономической безопасности коммерческого банка, в качестве входных параметров функции экономической безопасности рассмотрим показатели 1-5, поскольку они, согласно инструкции ЦБ 139-И, в полной мере характеризуют уровнь экономической безопасности кредитной организации. 
При построении аналитической модели исследуемого феномена будем рассматривать финансовые показатели крупнейшего банка России ПАО Сбербанк [6].

В целях более точного представления об уровне экономической безопасности ПАО Сбербанк и его динамике за последние пять лет рассмотрим следующие финансовые показатели: норматив достаточности собственных средств Н1.0 (ПБ1); рентабельность капитала (ПБ2); рентабельность активов-нетто (ПБ3); норматив мгновенной ликвидности Н2 (ПБ4); норматив текущей ликвидности Н3 (ПБ5) (см. рис. 1).

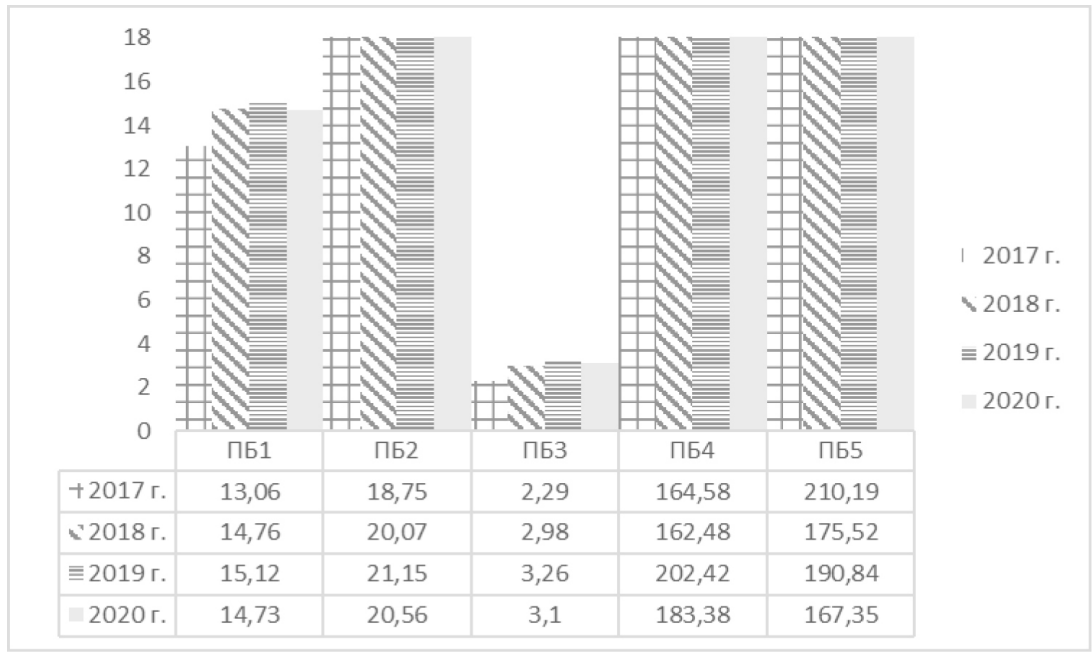

Рис. 1. Показатели ПБ1 - ПБ5 за 2017-2020 гг., \%

Норматив достаточности (ПБ1) ПАО Сбербанк за последний год незначительно, но уменьшился. Однако до минимально допустимого значения этого норматива ( $8 \%$ ) еще далеко. Оценим изменения показателя ПБ2. Эксперты считают, что потеря капитала ПАО Сбербанк может быть обусловлена выплатой дивидендов. Так, ПАО Сбербанк выплатил рекордные как для банка, так и для всех российских компаний 361 млрд.руб. в виде дивидендов (43,45\% от чистой прибыли по МСФО). Относительно показателя ПБЗ до 2019 года наблюда- 
лась исключительно положительная динамика. По итогам 2020 года наблюдалось незначительное снижение рентабельности капитала с $21,15 \%$ до 20,56\% (-0,59\%), рентабельности активов-нетто с 3,26\% до $3,1 \%$ (-0,16\%). Данная тенденция объясняется тем, что за указанный период увеличились операционные расходы ПАО Сбербанк (по данным статистики на 21,8\%). Их рост связан с изменением уровня оплаты труда и увеличением административно-хозяйственных расходов, что оказало давление как на рентабельность капитала, так и на рентабельность активов-нетто. Состояние ликвидности банка является важнейшей характеристикой его деятельности, позволяющей судить о надежности банка для клиента. Именно поэтому регулятор уделяет такое значение контролю за состоянием ликвидности банков в России. Анализируя динамику показателей Н2 (ПБ4) и Н3 (ПБ5), можно прийти к следующему заключению: угрозы для финансового состояния ПАО Сбербанк нет, поскольку снижение нормативов ликвидности незначительные.

Анализ экономической деятельности и статистические данные за анализируемый период ПАО Сбербанк свидетельствуют о наличии некоторых неблагоприятных тенденций, которые способны негативно сказаться на уровне экономической безопасности банка в перспективе.

\section{Результаты и обсуждение}

Оценка текущего состояния, мониторинг, прогнозирование развития сложных экономических систем являются классическими для экономической теории. Однако известные эконометрические модели в случае нелинейности исходных данных могут привести к весьма противоречивым результатам, поскольку при построении практических единых систем внедрение математических методов приводит к тому, что они выхватываются из общей системы экономической структуры, в результате модель объекта получается механистической. Перебор всевозможных причинно-следственных связей позволяют оценить степень угроз экономической безопасности только количественно, но не качественно. Анализ современных 
методов математического моделирования сложных экономических структур, касающихся оценки и обеспечения экономической безопасности, показал, что в качестве приоритетного можно выделить нейросетевое моделирование.

При выборе структуры нейронной необходимо особое внимание уделить формированию системы входных параметров, которая бы в полной мере соответствовала задачам моделирования.

Для построения нейросетевой модели экономической безопасности будем использовать вышеперечисленные показатели, функцию экономической безопасности представим в следующем виде:

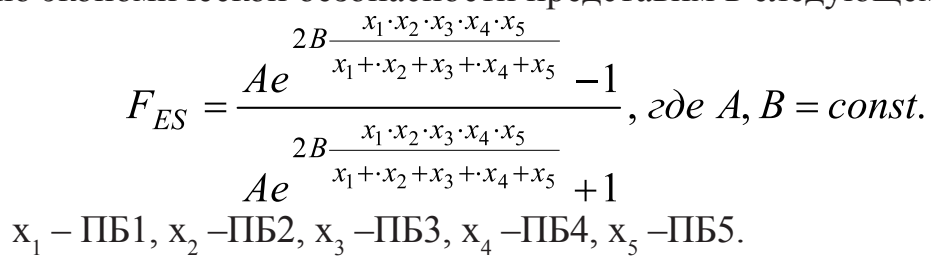

Этап обучения нейронной сети представляет собой последовательный отбор входных параметров - экономических показателей деятельности ПАО Сбербанк за 2017-2020 гг. Выходным значением является значения функции $\mathrm{F}_{\mathrm{ES}}$.

Входные параметры финансовых показателей представлены в таблице 1. Для построения нейросетевой модели был использован обработчик «Нейросеть» аналитической платформы Deductor Studio. Каждая строка таблицы содержит обучающий пример ( $\mathrm{x}_{1}$, $\mathrm{x}_{2}, \ldots, \mathrm{x}_{5}-$ входные значения сети) и ожидаемое значение выхода целевой функции $\left(\mathrm{F}_{\mathrm{ES}}\right)$.

Таблицуа 1 .

Входные параметры для построения нейронной сети за период 2017-2020 гг.

\begin{tabular}{|c|c|c|c|c|c|c|}
\hline Годы & $\mathrm{x}_{1}$ & $\mathrm{x}_{2}$ & $\mathrm{x}_{3}$ & $\mathrm{x}_{4}$ & $\mathrm{x}_{5}$ & $\mathrm{~F}_{\mathrm{ES}}$ \\
\hline 2016 & 13,06 & 18,75 & 2,29 & 164,58 & 210,19 & 0,79 \\
\hline 2017 & 14,76 & 20,07 & 2,98 & 162,48 & 175,52 & 0,88 \\
\hline 2018 & 15,12 & 21,15 & 3,26 & 202,42 & 190,84 & 0,97 \\
\hline 2019 & 14,73 & 20,56 & 3,10 & 183,38 & 167,35 & 0,94 \\
\hline
\end{tabular}

Следующий шаг процесса моделирования - проверка адекватности построенной модели. Для того чтобы модель была непротиво- 
речивой и соответствовала закономерностям описываемого феномена, необходимо оценить разницу между расчетными результатами функции и результатами, полученными в ходе моделирования. Возможности аналитической платформы позволяют в автоматическом режиме или оффлайн проверить модель на адекватность, сопоставив значения целевой функции на выходе нейронной сети с экспериментальными значениями (значения столбца FES_ERR отражают степень погрешности вычислений, см. табл. 2).

Таблииа 2.

Проверка адекватности, построенной нейросетевой модели

\begin{tabular}{|c|c|c|c|c|c|c|c|}
\hline & $\mathrm{x}_{1}$ & $\mathrm{x}_{2}$ & $\mathrm{x}_{3}$ & $\mathrm{x}_{4}$ & $\mathrm{x}_{5}$ & FES & FES_ERR \\
\hline 2016 & 13,06 & 18,75 & 2,29 & 164,58 & 210,19 & 0,79 & $3,826747 \mathrm{E}-12$ \\
\hline 2017 & 14,76 & 20,07 & 2,98 & 162,48 & 175,52 & 0,88 & $3,826747 \mathrm{E}-12$ \\
\hline 2018 & 15,12 & 21,15 & 3,26 & 202,42 & 190,84 & 0,97 & $3,826747 \mathrm{E}-12$ \\
\hline 2019 & 14,73 & 20,56 & 3,10 & 183,38 & 167,35 & 0,94 & $3,826747-12$ \\
\hline
\end{tabular}

Исходя из полученных значений функции экономической безопасности, видим, что полученные значения находятся в пределах 0,79-0,94. Это свидетельствует о том, что коммерческий банк соблюдает все требования Банка России. Его финансовое состояние находится под контролем. Подводя итог оценке уровня экономической безопасности ПАО Сбербанк, можно сделать вывод, что по всем оцениваемым показателям результаты функционирования банка находятся в норме. В ходе оценки мы получили достаточно высокие значения функции экономической безопасности.

\section{Заключение}

В рамках нашего исследования мы использовали аналитическую модель, выбор которой теоретически обоснован в работах [2; 4; 12], провели эмпирическое исследование, доказывающее состоятельность модели. Поскольку основным недостатком существующих методик и подходов является статичность полученного результата, отсутствие возможности прогнозирования текущего состояния либо субъективность экспертной оценки, то в рамках нашего исследования было предложено реализовать экономико-математиче- 
скую модель с помощью нейросети. Нейросетевое моделирование позволяет аппроксимировать функциональную зависимость между входными параметрами и целевыми значениями, причем, что является одним из главных преимуществ данного подхода, эта зависимость может иметь нелинейный характер. В рамках нейросетевого подхода существует возможность с заданной степенью точностью прогнозировать итоговые значения целевой функции - функции экономической безопасности. Автор считает, что подход ЦБ РФ, ранжирование кредитных организации на основе пресс-рейтинга, а также методика Кромонова В.С. не совсем подходят для индивидуального использования в целях, например, выбора кредитной организации для размещения и сохранения личных средств, принятия взвешенных и обоснованных управленческих решений, поскольку требуют глубокого статистического и теоретического анализа, что не совсем удобно. В свою очередь, алгоритм обучения нейронной сети, описанный ранее, позволяет выявлять закономерности между параметрами, прогнозировать возможные итоговые значения, что обеспечивает объективную экспертную оценку и обоснование принятия решений.

\section{Список литературы}

1. Буньковский Д.В. Иностранные инвестиции и экономическая безопасность России // Актуальные проблемы гуманитарных и социально-экономических наук. 2017. Т. 11, № 3. С. 32-33.

2. Гонтарь А.А. Нейросетевое моделирование в оценке уровня экономической безопасности систем // Смотр-конкурс научных, конструкторских и технологических работ студентов Волгоградского государственного технического университета (г. Волгоград, 16-20 апреля 2018 г.): тез. докл. / редкол.: А. В. Навроцкий (отв. ред.) [и др.]; Волгоградский гос. техн. ун-т, Совет СНТО. Волгоград, 2018. С. 181-182.

3. Гусев А. Е. Анализ эффективности методики Кромонова для оценки финансовой устойчивости банка // Теория и практика современной науки. 2017. № 5 (23). С. 238-243. 
4. Ермакова А.А. Прикладные математические методы оценки уровня экономической безопасности // Инновационные технологии в науке нового времени : сб. ст. междунар. науч.-практ. конф. (г. Новосибирск, 8 авг. 2016 г.). Уфа: Международный центр инновационных исследований (МЦИИ) «ОМЕГА САЙНС», 2016. С. 92-94.

5. Концепция национальной безопасности Российской Федерации, утвержденная Указом Президента РФ от 17 декабря 1997 г. [Электронный ресурс]. Режим доступа: http://www.consultant.ru (дата обращения 29.05.2021).

6. Официальный сайт Федеральной службы государственной статистики [Электронный ресурс]. Режим доступа: https://rosstat.gov.ru (дата обращения 29.05.2021).

7. Сенчагов В.К. Экономическая безопасность России. М.: Дело, 2013. $470 \mathrm{c}$.

8. Стратегия национальной безопасности Российской Федерации до 2020 года, утвержденная Указом Президента Российской Федерации от 12 мая 2009 г. № 537. [Электронный ресурс]. Режим доступа: http://www.consultant.ru (дата обращения 20.06.2021).

9. Указание Банка России от 11.06.2014 N 3277-У (ред. от 26.12.2017) «О методиках оценки финансовой устойчивости банка в целях признания ее достаточной для участия в системе страхования вкладов» (Зарегистрировано в Минюсте России 31.07.2014 № 33367). [Электронный ресурс]. Режим доступа: http://www.consultant.ru (дата обращения 19.05.2021).

10. Федотова Г.В. Алгоритмизация торговых стратегий фондового рынка / Г.В. Федотова, А.А. Ермакова, Д.А. Куразова // Национальные интересы: приоритеты и безопасность. 2016. № 11 (344). С. 87-95.

11. Fedotova G.V., Lomakin N.I., Gontar A.A., Tkachenko D.D. Peculiarities of Digital Transformation of the System of Bank's Economic Security The Future of the Global Financial System: Downfall or Harmony : [materials of conference (Limassol, Cyprus, April 13-14, 2018)], ed. by Elena G. Popkova. Cham (Switzerland) : Springer Nature Switzerland AG, 2019. pp. 1104-1112. (Book ser. Lecture Notes in Networks and Systems; Volume 57). 
12. Gontar A.A. Artificial Neural Network Model for Systems of Economic Security of Bank. IOP Conference Series: Earth and Environmental Science. International science and technology conference «Earth science» (Russky Island, Russian Federation, 4-6 March, 2019, Vol. 272. 6 p. https://iopscience.iop.org/article/10.1088/1755-1315/272/3/ 032176/pdf

13. Gontar A.A. Ensuring economic safety: regional aspects. Proceedings of the International Scientific Conference «Competitive, Sustainable and Secure Development of the Regional Economy: Response to Global Challenges» (CSSDRE 2018). Cep. «Advances in Economics, Business and Management Research» Editor Elena G. Russkova, Director, Institute of Economics and Finance, Volgograd State University. 2018. pp. 737-740.

14. Jiang Yong. Economic Security: Redressing Imbalance // China Security. 2008. Vol. 3, No. 2. pp. 54-60.

15. Kirshner J. Political Economy in Security Studies after the Cold War. // Review of International Political Economy. 1998. No. 1 (5). P. 78.

16. Murdoch C. Economics Issues \& National Security. Lawrence, 2012. P. 136.

\section{References}

1. Bun'kovskij D.V. Inostrannye investicii i jekonomicheskaja bezopasnost' Rossii [Foreign investment and Russia's economic security]. Aktual'nye problemy gumanitarnyh $i$ social'no-jekonomicheskih nauk [Actual problems of Humanities and socio-economic Sciences], 2017, vol. 11, no. 3, pp. 32-33.

2. Gontar' A.A. Nejrosetevoe modelirovanie v ocenke urovnja jekonomicheskoj bezopasnosti sistem [Neural network modeling in assessing the level of economic security of systems], Smotr-konkurs nauchnyh, konstruktorskih i tehnologicheskih rabot studentov Volgogradskogo gosudarstvennogo tehnicheskogo universiteta (g. Volgograd, 16-20 aprelja 2018 g.) [Review-competition of scientific, design and technological works of students of Volgograd State Technical University, Volgograd, April16-20, 2018]. Volgograd, 2018, pp. 181-182. 
3. Gusev A.E. Analiz jeffektivnosti metodiki Kromonova dlja ocenki finansovoj ustojchivosti banka [Analysis of the effectiveness of the Kromonov method for assessing the financial stability of a Bank]. Teorija i praktika sovremennoj nauki [Theory and practice of modern science], 2017, no. 5 (23), pp. 238-243.

4. Ermakova A.A. Prikladnye matematicheskie metody ocenki urovnja jekonomicheskoj bezopasnosti [Applied mathematical methods for assessing the level of economic security]. Innovacionnye tehnologii $v$ nauke novogo vremeni : sb. st. mezhdunar. nauch.-prakt. konf. (g. Novosibirsk, 8 avg. 2016 g.). Ufa: Mezhdunarodnyj centr innovacionnyh issledovanij (MCII) «OMEGA SAJNS» [Innovative technologies in the science of the new time: collection of articles of the international journal. scientific and practical Conf. (Novosibirsk, 8 Aug. 2016). Ufa: international center for innovative research (ICI) «OMEGA SCIENCE»], 2016, pp. 92-94.

5. Koncepcija nacional'noj bezopasnosti Rossijskoj Federacii, utverzhdennaja Ukazom Prezidenta RF ot 17 dekabrja $1997 \mathrm{~g}$. [The concept of national security of the Russian Federation, approved by the Decree of the President of the Russian Federation of December 17, 1997]. http:// www.consultant.ru (accessed 29.05.2021).

6. Oficial'nyj sajt Federal'noj sluzhby gosudarstvennoj statistiki [Official site of Federal State Statistic Service]. https://rosstat.gov.ru (accessed 29.05.2021).

7. Senchagov V.K. Jekonomicheskaja bezopasnost' Rossii [Russia's economic security]. Moscow, Delo Publ., 2013. 470 p.

8. Strategija nacional'noj bezopasnosti Rossijskoj Federacii do 2020 goda, utverzhdennaja Ukazom Prezidenta Rossijskoj Federacii ot 12 maja 2009 g. № 537. [The National Security Strategy of the Russian Federation until 2020, approved by the Decree of the President of the Russian Federation dated May 12, 2009, No. 537]. http://www.consultant.ru (accessed 20.06.2021).

9. Ukazanie Banka Rossii ot 11.06.2014 N 3277-U (red. ot 26.12.2017) "O metodikah ocenki fi-nansovoj ustojchivosti banka v celjah priznanija ee dostatochnoj dlja uchastija v sisteme strahovanija vkladov" (Zaregistrirovano v Minjuste Rossii 31.07.2014 № 33367) [Bank of Russia 
Ordinance dated June 11, 2014 N 3277-U (as revised on December 26, 2017) "On methods for assessing the financial stability of a bank in order to recognize it as sufficient for participation in the deposit insurance system" (Registered with the Ministry of Justice of Russia on July 31, 2014 № 33367)]. http://www.consultant.ru (accessed 19.05.2021)

10. Fedotova G.V., Ermakova A.A., Kurazova D.A. Algoritmizacija torgovyh strategij fondovogo rynka [Algorithmization of stock market trading strategies], Dajdzhest-Finansy [Digest-Finance], 2019, vol. 24 (2), pp. 180-190.

11. Fedotova G.V., Lomakin N.I., Gontar A.A., Tkachenko D.D. Peculiarities of Digital Transformation of the System of Bank's Economic Security The Future of the Global Financial System: Downfall or Harmony : [materials of conference (Limassol, Cyprus, April 13-14, 2018)], ed. by Elena G. Popkova. Cham (Switzerland) : Springer Nature Switzerland AG, 2019. pp. 1104-1112. (Book ser. Lecture Notes in Networks and Systems; Volume 57).

12. Gontar A.A. Artificial Neural Network Model for Systems of Economic Security of Bank. IOP Conference Series: Earth and Environmental Science. International science and technology conference «Earth science» (Russky Island, Russian Federation, 4-6 March, 2019, Vol. 272. 6 p. https://iopscience.iop.org/article/10.1088/1755-1315/272/3/032176/pdf

13. Gontar A.A. Ensuring economic safety: regional aspects. Proceedings of the International Scientific Conference "Competitive, Sustainable and Secure Development of the Regional Economy: Response to Global Challenges" (CSSDRE 2018). Cep. "Advances in Economics, Business and Management Research" Editor Elena G. Russkova, Director, Institute of Economics and Finance, Volgograd State University, 2018, pp. 737-740.

14. Jiang Yong. Economic Security: Redressing Imbalance. China Security, 2008, vol. 3, no. 2, pp. 54-60.

15. Kirshner J. Political Economy in Security Studies after the Cold War. Review of International Political Economy, 1998, no. 1 (5), p. 78.

16. Murdoch C. Economics Issues \& National Security. Lawrence, 2012, p. 136. 


\section{ДАННЫЕ ОБ АВТОРЕ}

Гонтарь Анастасия Александровна, доцент кафедры, кандидат педагогических наук, доцент

Военный институт (инженерно-технический) ВА МТО

ул. Захарьевская, 22, г. Санкт-Петербург 191123, Российская Федерация

261984@mail.ru

\section{DATA ABOUT THE AUTHOR}

Anastasia A. Gontar, Ph.D. (Pedagogy), Associate Professor

Military Engineering-Technical University

22, Zakharyevskaya Str., St. Petersburg, 191123, Russian Federation

261984@mail.ru

SPIN-code: 8066-3740

ORCID: 0000-0003-1805-3744 